\title{
(3):

\section{The Middle-Income Trap: Comparing Asian and Latin American Experiences}

by Anna Jankowska, Arne J. Nagengast and José Ramón Perea

- Chinese Taipei; Hong Kong, China; Korea and Singapore (the East Asian Newly Industrialised Countries or NICs) have been successful in attaining income convergence with high-income countries while Latin American countries remain caught in the Middle-Income Trap.

- The East Asian NICs pursued export-led growth by targeting strategic industries which facilitated gradual diversification and upgrading into new products that required similar skills and inputs.

- Comparing the experience of the NICs to Latin American economies reveals that successful diversification and upgrading of a country's export structure requires coherent and complimentary policies in the areas of education, infrastructure, innovation and access to finance.

More than a decade of robust and sustained economic growth in emerging economies is contributing to a trend of increasing convergence in per capita income with high income countries and the shift of the economic centre of gravity towards the south and east (OECD Development Centre, 2010). These trends also bring new economic challenges to the forefront. This is particularly true for countries entering the middle zone of per capita income distribution. Over the last decade, 28 new countries have reached middle-income status (USD 1005 - USD 12075 Gross National Income or GNI per capita using the Atlas method as defined by the World Bank), while only 12 countries have graduated into high-income country status (more than USD 12076 GNI per capita). This suggests that, at middle levels of income, economic growth and structural upgrading become more arduous - the so-called Middle-Income Trap.

The experience of Latin American with the Middle-Income Trap has been very different from that of the NICs. While the latter were able to surpass middle-income status in a relatively brief period of time, Latin American countries have remained in the middle-income zone for decades. This contrast can serve as an illustrative basis for comparison for new countries entering the middle-income group.
The East Asian NICs' recipe for income convergence: gradual upgrading towards higher value industries

The Asian NICs' experiences suggest that escaping the Middle-Income Trap is a function of structural transformation through diversification into a greater number of products, as well as movement into higher value-added products over time. OECD Development Centre analysis based on the Product Space methodology (Hidalgo et al., 2007), which maps the relative proximity or similarity of traded products, shows that in the case of the Asian NICs, economic transformation was a gradual process. New production was sequentially developed in industries (e.g. iron, steel, machinery and electronics) using skills and capabilities transferable with relative ease from existing industries. This strategic increase in high "connectivity" sectors allowed these countries to undertake a gradual yet systematic transition towards higher value added activities, especially those requiring similar technology and production techniques (see Product Space map of Korea below). 


\section{Product Space Maps of Peru and Korea, 2009}
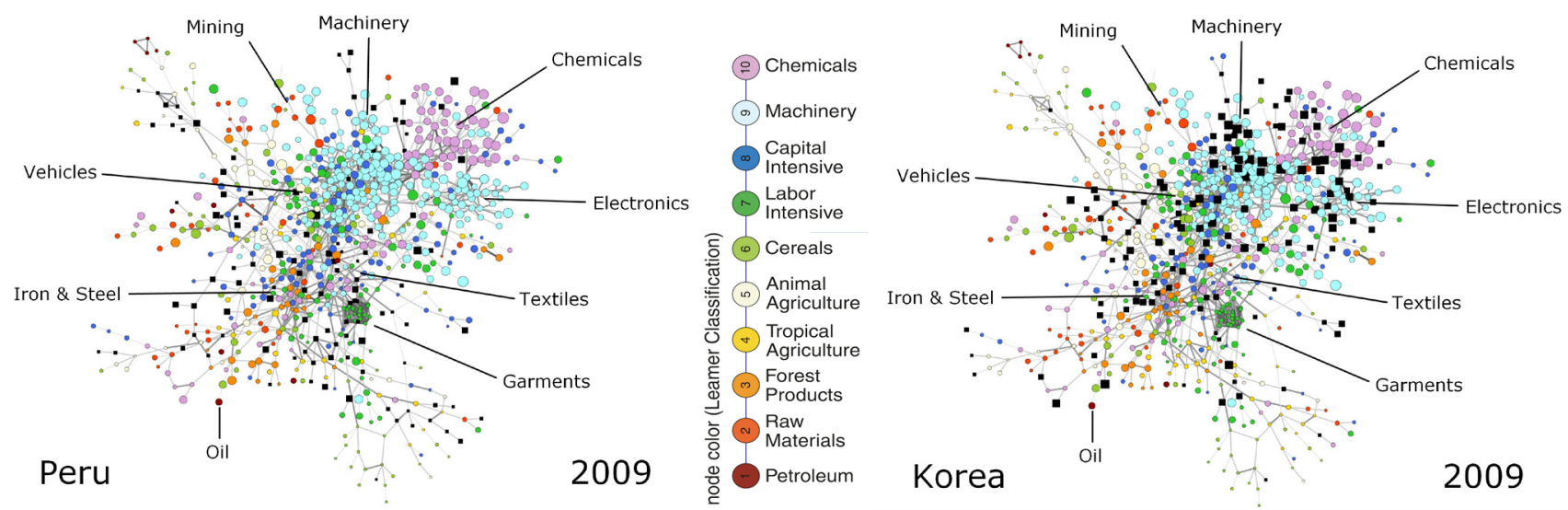

Note: The Product Space methodology provides a map of all traded goods displaying relative proximity or similarity between products. The colours on the map represent the Leamer classification which categorises products according to labour, capital and other resource intensiveness. The black squares indicate products in which the country has a revealed comparative advantage.

By contrast, Latin American countries tend to be characterised by economic specialisations in industries that are relatively far from high value-added industries, with lower connectivity overall in their export profiles (see Product Space map of Peru). Part of this divergence in ability to upgrade their export structure has to do with relative levels of productive capabilities or the specific skills and inputs available, which have been shown to be predictive of future GDP growth (Hidalgo and Hausmann, 2009). Latin American countries, with the exception of Brazil and Mexico, show capabilities that tend to be below the global average, whereas the Asian NICs and China already had high values in the capability measure in the 1960s and have since reached values substantially above the global average. These differences in productive capabilities highlight the importance of complimentary policies in facilitating economic transformation.

\section{Getting the right mix of policies}

Korea is an illustrative example of how the Asian NICs put in place policies to support diversification and productive upgrading. Korea's capacity to benefit from trade-led growth in high connectivity and value-added sectors relied heavily on implementing the right combination of productive and complimentary policies. As Korea moved through its successive Five Year Plans for economic development beginning in the 1960 s, its productive development policies targeted light manufacturing; then heavy chemicals, iron and steel; followed by shipbuilding and heavy machinery; and then electronics and knowledgeintensive industries. Throughout these productive phases, Korea aligned complimentary policies to meet particular industry needs. For example, in education policy, Korea initially focused on primary education during the light

Readers are encouraged to quote or reproduce material from OECD Development Centre Policy Insights for their own publications. In return, the Development Centre requests due acknowledgement and a copy of the publication. Full text of Policy Insights and more information on the Centre and its work are available on its web site: www.oecd.org/dev manufacturing phase, and invested more heavily in secondary education and technical training to provide skills for heavier industries, and shifted towards higher education with the subsequent move into electronics and knowledge-intensive industries. Similar trends of adapting complimentary policies to specific industry needs were visible in the areas of financing, with credit directed towards target industries, as well as innovation policies, providing fiscal incentives for the creation of $R \& D$ centres, and venture capital for high-tech start ups. This policy alignment was critical for providing the necessary skilled labour to move into higher value-added industries, assuring sufficient capital to develop productive capacities, as well as supporting research and innovation in more knowledge-intensive sectors. For Latin America and other countries currently in the middle-income zone, the Korean experience underscores the importance of supporting productive development with the appropriate complimentary policies, particularly in order to facilitate the gradual and path-dependent economic transformation necessary for income convergence.

\section{Further reading}

HIDALGO, C. A., B. KLINGER, A.L. BARABÁSI, and R. HAUSMANN (2007). "The Product Space Conditions the Development of Nations", Science, 317(5837), 482-487.

HIDALGO, A. C. and R. HAUSMANN (2009), "The building blocks of economic complexity", Proceedings of the National Academy of Sciences, 106(26), 10570-10575.

JANKOWSKA, A., A. J. NAGENGAST and J. R. PEREA (2012), "The Product Space and the Middle Income Trap: Comparing Asian and Latin American Experiences", OECD Development Centre Working Paper No. 311.

OECD DEVELOPMENT CENTRE (2010) Perspectives on Global Development.

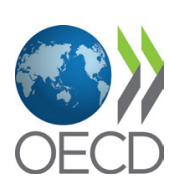

